\title{
TEMPAT PETUALANGAN KULINER DI STASIUN PESING
}

\author{
Evan Hansabian ${ }^{1)}$, Martin Halim²) \\ 1) Program Studi S1 Arsitektur, Fakultas Teknik, Universitas Tarumanagara, ehansabian9@gmail.com \\ 2) Program Studi S1 Arsitektur, Fakultas Teknik, Universitas Tarumanagara, martinhalim90@gmail.com
}

\begin{abstract}
Abstrak
Tempat ketiga itu sangat penting bagi kehidupan manusia, dimana tempat pertama adalah rumah yang kita tinggali sehari-hari, tempat kedua adalah dimana kita bekerja untuk mendapatkan penghasilan, bagaimana dengan tempat ketiga? Ini yang akan diangkat oleh seorang arsitek, bagaimana cara merancang sebuah tempat ketiga bagi orang-orang sekitar agar bisa menciptakan kualitas yang baik. Dengan pendekatan fenomenologi, banyak hal yang harus diperhatikan secara detail, karena tempat makan di stasiun pesing jumlahnya sangat kurang, tidak bersih, dan tidak terintegrasi, sehingga membuat pengunjung sekitar kurang menikmati daerah tersebut. Secara tidak sadar di dalamnya terdapat sebuah memori pemberi nilai sejarah tentang kuliner nusantara yang sudah memudar di Jakarta dan di lengkapi dengan aktivitas-aktivitas lokal pendukung lainya seperti theater outdoor, pedestrianmall, cafe khas nusantara, dan makanan penutup nusantara, kerena ingin mengangkat budaya dan kebiasaan masyarakat di indonesia. Karena lokasi yang dekat dengan stasiun kereta api, maka co-working space menjadi program tambahan di tempat kuliner ini, dimana orang yang ingin bekerja tidak perlu menyewa gedung perkantoran. dengan adanya beberapa tempat makan yang sederhana, mereka cukup mudah untuk mencari makan dan sarana hiburan lainya. Disana terdapat ojek online yang beroperasi di depan ibis hotel tetapi cukup menghambat jalur lalu lintas dan menimbulkan kemacetan, maka foodstreet menjadi tempat peristirahatan bagi pengunjung stasiun, ojek online, dan ojek pengkolan agar tidak mengganggu jalur lalu lintas. Dengan hadirnya tempat petualangan kuliner di stasiun Pesing ini diharapkan dapat meningkatkan interaksi sosial di lingkungan sehari-hari, dapat meminimalisir kemacetan yang ada di depan stasiun, menambah wawasan tentang kuliner nusantara dan menjadi tempat ketiga bagi wilayah Grogol petamburan.
\end{abstract}

Kata kunci: arsitek; kuliner; petualangan; interaksi

\begin{abstract}
A thirdplace is very important on our daily basis, where the firstplace is a dwelling we live in, the secondplace is where we work to earn a living, and what about the thirdplace? This is what will be brought up by an architect of how do we scheme a thirdplace for others to create a good quality. With a phenomenological approach, many things must be considered in detail because the number of places to eat at Pesing Station are lack, unclean, and unintegrated, that made the visitors less enjoying this area. Unconsciously in it has a memory of historical value about local culinary that has faded in Jakarta and completed by some supportive local activities such as outdoor theater, pedestrian mall, local typical cafes, and local desserts, to raise the culture and habits of people in Indonesia. Since the location is close to the train station, co-working space become an additional program in this culinary place, where people who wants to work do not need to rent an office building. With a few simple eating places, they are quite convinient to find food and other entertainment facilities. There are online motorcycle taxis operating in front of Ibis hotel but hamper the traffic lanes and cause traffic jams, so the foodstreet will be a resting place for station visitors, and both online and offline motorcycle taxis to avoid disrupting the traffic. The presence of this food adventure place in Pesing Station is expected to improve the quality of social life in the environment around us, minimize the traffic congestion in front of the station, adding some knowledge about local foods, and be a thirdplace in Grogol Petamburan area.
\end{abstract}

Keywords: architect; culinery; adventure; interactive 


\section{PENDAHULUAN}

Dijakarta ini cukup terkenal dengan yang namanya kemacetan lokal, dan ini menjadi konsen para arsitek untuk meminimalisir kemacetan di Jakarta, masalah di Jakarta ini adalah padatnya kendaraan umum maupun pribadi, minimnya lahan hijau, banyaknya bangunan-bangunan komersial secara berlebihan dan pertumbuhan penduduk yang cukup pesat, maka dari itu kemacetan akan muncul. Apa hubungannya dengan the thirdplace? potensi dan arti dari the thirdplace itu sendiri yang cukup untuk menjawab permasalahan yang ada di Jakarta, tetapi the thirdplace yang seperti apa untuk menjawab kemacetan lokal yang ada di Jakarta.

Terutama di kelurahan wijaya kesuma, di stasiun pesing, dimana terdapat ojek online yang sedang beristriahat di depan stasiun sekaligus menunggu penumpang yang datang, disana cukup menghambat alur transportasi umum maupun pribadi sehingga menimbulkan kemacetan, ditambah luas jalan yang tidak memadai, tidak hanya ojek online, beberapa angkotpun banyak yang menunggu disana. Maka dari itu foodstreet adalah jawaban untuk menyelesaikan kemacetan di stasiun pesing, karena dengan adanya foodstreet, para ojek online maupun pengkolan dapat beristirahat disana tanpa mengganggu jalur lalu lintas. Di sekitar stasiun pesing terdapat pedagang kaki lima yang cukup liar, sehingga membuat lingkungan tersebut kurang terintegrasi, kurang bersih dan kurang memadai, sehingga membuat para pengguna sekitar kurang nyaman untuk beraktivitas di lingkungan tersebut, maka dari itu kuliner nusantara adalah jawaban untuk menciptakan tempat makan yang bersih, terintegrasi, dan sederhana. ditambah lagi dengan minimnya ruang terbuka hijau di daerah tersebut, dimana fungsi ini yang dibutuhkan oleh masyarakat sekitar untuk melakukan aktivitas sosialnya, dengan adanya RTH di perancangan ini, dapat menambah resapan di kawasan grogol dan menjadi tempat aktivitas sosial bagi masyarakat sekitar. disana juga tidak ada sarana performance untuk menarik perhatian pengunjung sehingga membuat area sekitar stasiun terlihat sepi dan kaku, dengan adanya theater outdoor maka suasana disekitar lebih hidup dan berwarna serta semua kalangan bisa menikmati pertunjukan itu. untuk menambah tunjangan di kawasan ini, maka dibuat tempat untuk co workingspace, dikarenakan disana tidak ada tempat kerja yang menyenangkan didekat stasiun pesing dan akses yang sangat mudah dijangkau oleh pengguna.

\section{KAJIAN LITERATUR}

Dari kejadian yang ada di kelurahan Wijaya Kusuma ini, munculah berbagai teori-teori yang membantu menyelesaikan masalah yang ada di Kawasan tersebut, salah satunya adalah teori the third place dan teori tentang pedestrian food

\section{The third place}

Konsep third place yang dikemukakan oleh Oldenburg(1999) sebagai pembentuk ruang interaksi sosial. Pengertian third place menurut Oldenburg(1999) yang menyatakan bahwa third place merupakan tempat untuk orang yang ingin mengobati stress, kesepian, dan keterasingan. Sakah satu tempat yang bisa dijadikan tempat berlindung sementara dari kebosanan. Tidak hanya dijadikan tempat untuk melarikan diri,tetapi dimana orang akan bersantai dan terasa terhiburdan juga mendapatkan ketenangandi dalamnya. Pada third place orang melarikan diri dari first place (rumah) dan second place (tempat kerja atau sekolah) untuk membuka jati dirinya dan bertujuan untuk bersosialisasi di dalamnya. Berdasarkan penelitiannya, Oldenburg (1999) mengungkap 8 (delapan) karakter yang membentuk third place yaitu on neutral ground, leveler, conversation is the main activity, accessibility andaccomodation, the regulars, low profile, mood is playful, dan a home away from home.

\section{Menurut Christopher Peterson ciri-ciri the third place adalah}

- Pertama, netral, artinya semua orang bisa datang dan pergi tanpa penalti. Jika tidak pergi ke tempat ketiga selama beberapa hari atau minggu, pengembalian disambut dengan minat dan antusiasme. Bandingkan dengan pekerjaan atau rumah, di mana akhirnya kembali setelah berhari-hari absen akan disambut dengan slip merah muda atau surat cerai. 
- Kedua, level, artinya perbedaan status yang sangat penting di tempat lain tidak relevan. Dan tidak ada yang memainkan tuan rumah di tempat ketiga.

- Ketiga, percakapan adalah kegiatan utama di tempat ketiga, dan salah satu dari beberapa cara untuk menyinggung orang lain yang hadir adalah menjadi membosankan.

- Keempat, tempat ketiga dapat diakses, artinya memiliki jam yang panjang dan mudah dijangkau. Tidak perlu reservasi!

- Kelima, tempat ketiga memiliki pengunjung tetap. Memang, pelanggan tetap menentukan tempat ketiga, tetapi orang baru diterima, tidak secara otomatis tetapi sering dengan mudah.

- Keenam, tempat ketiga secara fisik sederhana dan bersahaja.

- Ketujuh, dan mungkin yang paling kritis, suasana dominan dari tempat ketiga adalah menyenangkan. Banyak tawa

- Tempat ketiga berkontribusi pada kehidupan yang layak dijalani. Memungkinkan menjadi diri sendiri. Dan semua orang tahu.

konsep third place yang dikemukakan oleh Oldenburg(1999) sebagai pembentuk ruang interaksi sosial.Pengertian third place menurut Oldenburg(1999) yang menyatakan bahwathird placemerupakan tempat untuk orang yang inginmengobati stress, kesepian, dan keterasingan. Pengertian dari third placeadalah suatu tempatyang bisa dijadikan tempatberlindung sementara dari kebosanan. Tidak hanya dijadikantempat untuk melarikan diri, tetapi dimana orang akan bersantai dan terasa terhiburdan juga mendapatkan ketenangandi dalamnya. Pada third placeorang melarikan diri dari first place(rumah) dan second place(tempat kerja atau sekolah)untuk membuka jati dirinya dan bertujuan untuk bersosialisasi di dalamnya. Berdasarkan penelitiannya, Oldenburg(1999) mengungkap 8 (delapan) karakter yang membentuk third placeyaituon neutral ground, leveler, conversation is the main activity, accessibility andaccomodation, the regulars, low profile, mood is playful, dan a home away from home.

\section{Pedestrian food}

Pedestrian berasal dari Bahasa Yunani yaitu pedosatau pedester-pedestrisyang berarti kaki, jadi pedestrian adalah pejalan kaki. Pejalan kaki adalah pergerakan atau perpindahan manusia dari suatu tempat ketempat lainnya (Danoe, 2006). Pemerintah mengatur hak pejalan kaki pada UU No 22 tahun 2009 yaitu "setiap lalu lintas jalan harus dilengkapi dengan perlengkapan jalan". Perlengkapan jalan yang dimaksud adalah fasilitas pedestrian. sudah selayaknya pejalan kaki bisa menikmati fasilitas pedestrian. Perencanaan dan perancangan fasilitas pedestrian yang memenuhi kebutuhan penggunanya akan mendorong minat seseorang untuk berjalan karena dengan berjalan individu akan mendapat banyak manfaat.

Menurut Ariffin dan Zahari (2013) manfaat dari berjalan kaki yaitu jika dilihat dari aspek ekonomi, dapat mengurangi biaya transportasi dan keuntungan dikawasaan komersial dapat menghidupkan aktivitas perdagangan, dari aspek sosial yaitu dapat meningkatkan interaksi dengan masyarakat serta jika dilihat dari aspek manfaat lingkungan yaitu dapat mengurangi ketergantungan terhadap kendaraan sehingga bisa meningkatkan kualitas lingkungan karena berkurangnya polusi udara dan konsumsi energi.Faktor-faktor yang mempengaruhi jarak tempuh pejalan kaki (Pattisinai, 2013) yaitu:(1) waktu, (2) kenyamanan, (3) tata guna lahan dan (4) ketersediaan kendaraan. Berjalan kaki pada waktu tertentu mempengaruhi jarak berjalan yang mampu ditempuh. Misalnya individu yang berjalan untuk tujuan berbelanja akan berjalan lebih jauh tanpa disadari. Sebab berjalan dengan tujuan belanja dilakukan dengan santai dan biasanya kecepatan berjalan lebih rendah. Pada penelitian yang dilakukan oleh Danoe (2006) usia juga mempengaruhi jarak tempuh serta kecepatan berjalan kaki. Kategori orang dewasa cenderung berjalan lebih cepat dibandingkan dengan anak-anak dan orang tua.Cuaca dan jenis aktivitas juga mempengaruhi kenyamanan pejalan kaki (Pattisinai, 2013). Indonesia memiliki iklim tropis dengan cuaca yang panas dan lembab. Apabila pejalan kaki terpapar langsung oleh sinar matahari maka akan mengurangi minat untuk 
beraktivitas. Pejalan kaki pada dasarnya membutuhkan ruang untuk dapat terhindar dari paparan sinar matahari langsung dan cuaca buruk.

Makanan adalah segala sesuatu yang dapat dimakan dan setelah dicerna serta diserap tubuh akan berguna bagi kesehatan dan kelangsungan hidup. Menurut sumber,makanan adalah bahan, biasanya berasal dari hewan atau tumbuhan, yang dimakan oleh makhluk hidup mendapatkan tenaga dan nutrisi. Maka dari itu pedestrian food adalah tempat dimana orangorang bisa berinteraksi sambil menikmati makanan tanpa menggunakan kendaraan umum atau pribadi, sehingga dapat mengurangi polusi di wilayah tersebut dan membuat orang sekitar nyaman untuk menikmati makanan sekaligus berinteraksi.

\section{METODE}

Dari berbagai metode perancangan yang ada, metode fenomenologilah yang dipakai untuk membantu proses perancangan ini.

\section{Fenomenologi}

"Phenomenology is a strand of continental European philosophy that aims to understand the world from the experience of being an embodied presence in it." - Richard Weston

Dari kejadian yang sudah diamati di lingkungan tersebut, dilihat bahwa kebiasaan-kebiasaan masyarakat sekitar disana tidak begitu perduli dengan lingkungan sekitarnya, seperti ada beberapa sampah di dekat orang-orang disana, orang-orang itu terlihat tenang dan merasa nyaman, ada beberapa masyarakat disana tidak nyaman dikarenakan tempat yang kumuh, kotor, dan tidak teratur. masyarakat belum sadar akan pentingnya lingkungan, dan orang sekitar. Dengan adanya ojek online yang sedang beristirahat di trotoar sambil minum, ojek online juga tidak sadar dengan sampah yang dibuat sendiri, itu sangat merugikan bagi pengunjung stasiun dan sekitarnya, apalagi letaknya di depan ibis hotel, ditambah para ojek online menaruh motornya di tepi jalan yang dapat menghambat alur transportasi, dampaknya bisa mengurangi nilai jual yang ada di sekitar stasiun pesing termasuk ibis hotel itu. untuk fasilitas ibadah disana cukup tertib dan bersih, tidak ada sampah makanan sama sekali disana sehingga orang-orang yang ingin beribadah disana tetap merasa nyaman.

Kondisi RTH yang ada di kelurahan wijaya kesuma cukup baik, tetapi lokasi nya kurang strategis dikarenakan dekat dengan pusat pembuangan sampah sehingga masyarakat enggan untuk menikmati ruang terbuka hijau itu. Aktivitas pengunjung stasiun hanya pergi pulang saja, terkadang membeli makanan di pedagang kaki lima, terkadang ada yang langsung pulang menuju kerumahnya, tidak ada aktivitas lainnya untuk pengunjung stasiun. Dari fenomena yang ada, bisa didapatkan apa yang dibutuhkan untuk memperbaiki kondisi Kawasan yang kurang baik ini.

\section{DISKUSI DAN HASIL}

\section{Diskusi}

Data dan Analisis Lokasi Proyek

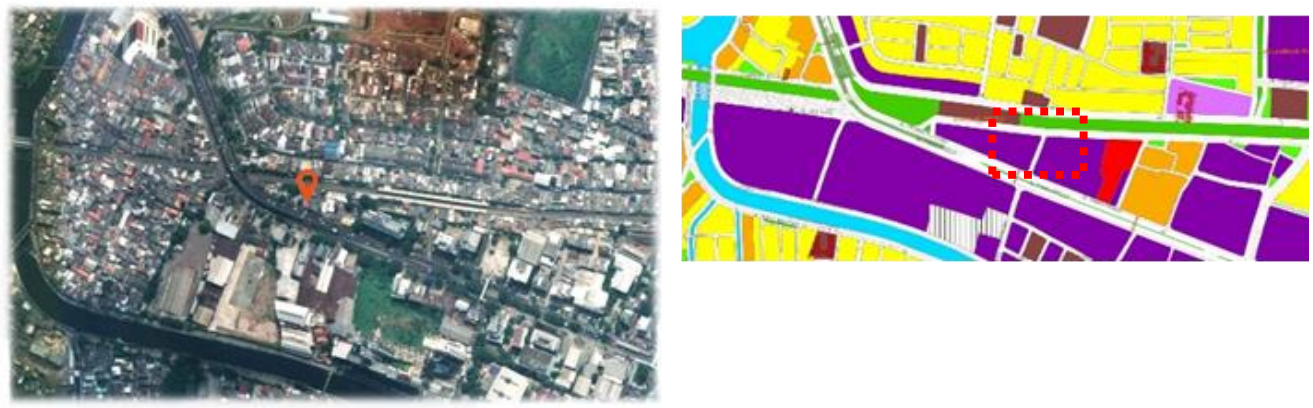

Gambar 1. wilayah Grogol Petamburan dan zonasi

Sumber: google maps yang sudah di olah 
Tempat petualangan kuliner ini berlokasi di wilayah grogol petamburan kelurahan Wijaya kesuma, di Jl Daanmogot Raya, lokasi ini dipilih dikarenakan ada beberapa isu masalah dan menyebabkan terhambatnya jalur lalulintas, zona ini adalah komersial, perdagangan, dan jasa. Tapak ini berada diantara firstplace dan secondplace dengan status sosial penduduk menengah kebawah sampai menengah keatas sehingga kriteria thirdplace akan muncul.

\section{Proses gubahan masa}

Setelah mendapatkan hasil dari pendekatan fenomenologi, dilanjutkan dengan proses gubahan massa untuk menciptakan sebuah thirdplace di tapak ini.

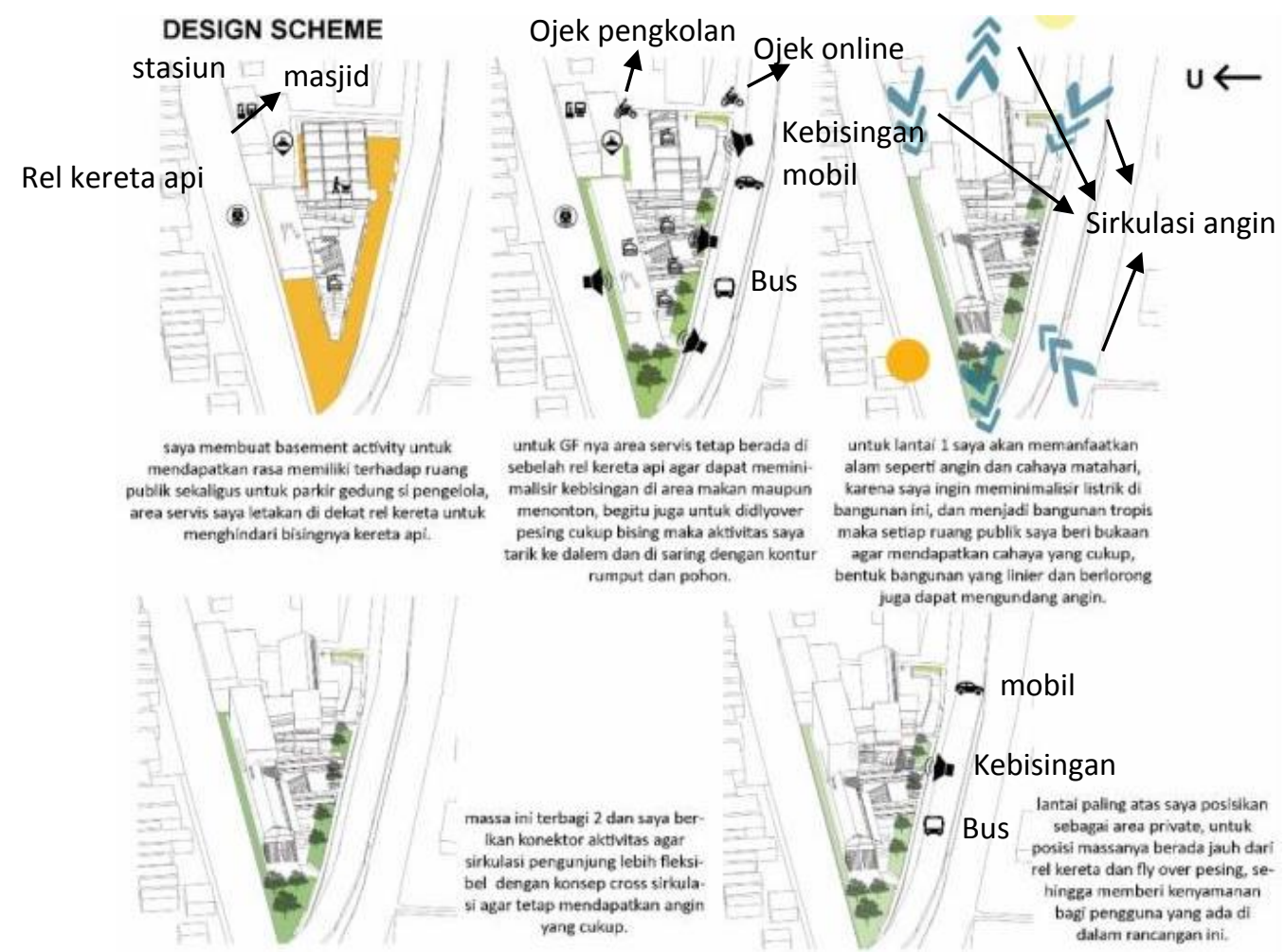

Gambar 2. Proses Gubahan Massa

Sumber: Penulis, 2019

\section{Desain akhir}

Theater outdoor

Theater outdoor Ini adalah tempat untuk melakukan aktivitas dimana mereka setelah makan atau melakukan aktivitas sehari-hari, mereka bisa menonton film yang ada disana sampai malam, sehingga bisa meningkatkan kualitas interaksi antar pengujung di tempat ini.

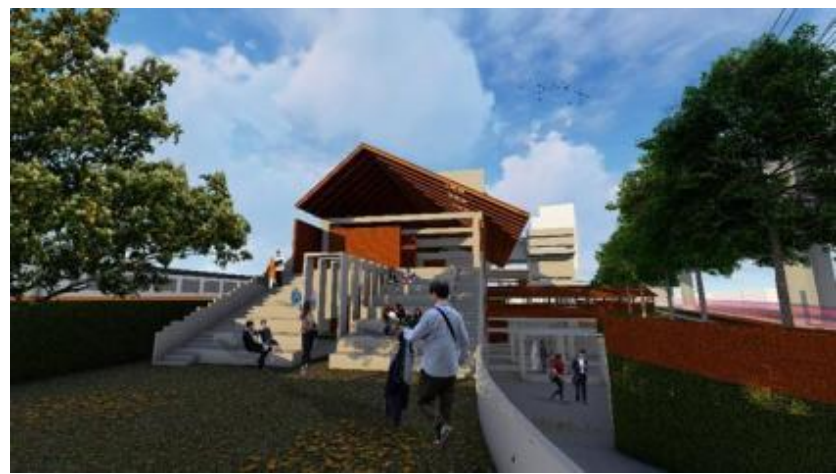

Gambar 3. Theater Outdoor

Sumber: Penulis, 2019 


\section{Akses utama rancangan}

Untuk akses utama disini tidak menggunakan pintu atau gerbang, karena tempat ini bisa diakses oleh siapapun dan darimana pun, sehingga tidak membuat perbedaan antara pejalan kaki maupun pengunjung di tempat kuliner ini, tempat ini bisa menjadi tempat beristirahat bagi pejalan sekitar.

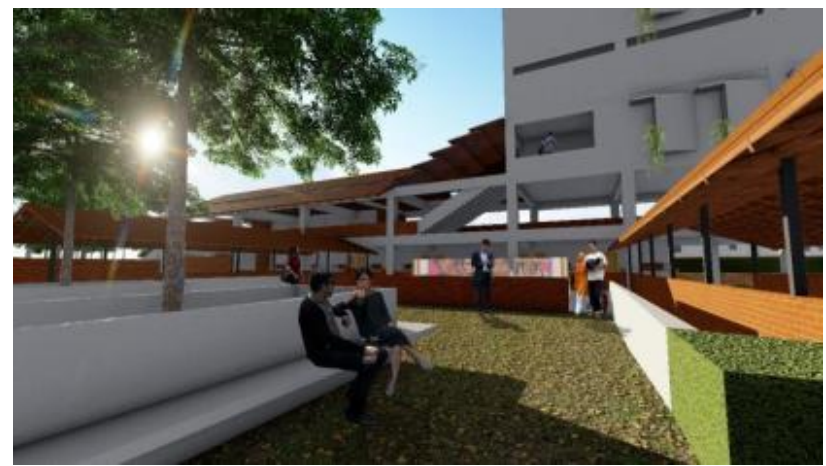

Gambar 4. Akses utama rancangan Sumber: Penulis, 2019

\section{Nusantara foodstreet}

Ini adalah foodstreet yang menghubungkan antara ojek online dengan offline serta pengunjung stasiun untuk mereka beristirahat sambil menikmati jajanan yang tersedia disana.

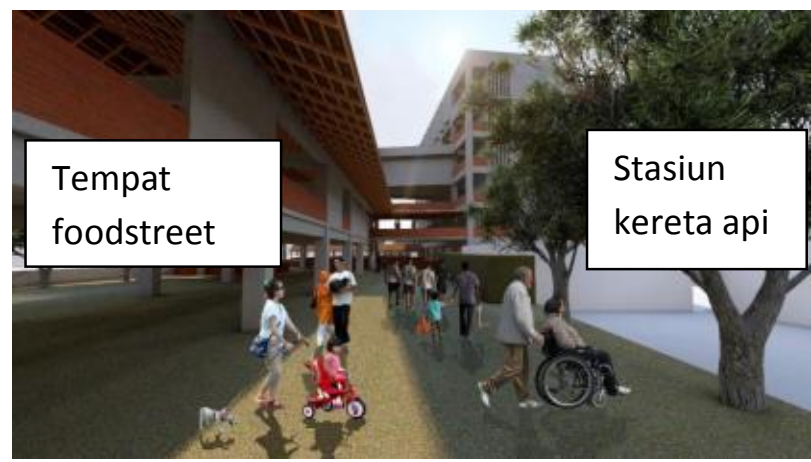

Gambar 5. Nusantara foostreet Sumber: Penulis, 2019

\section{Denah perancangan}

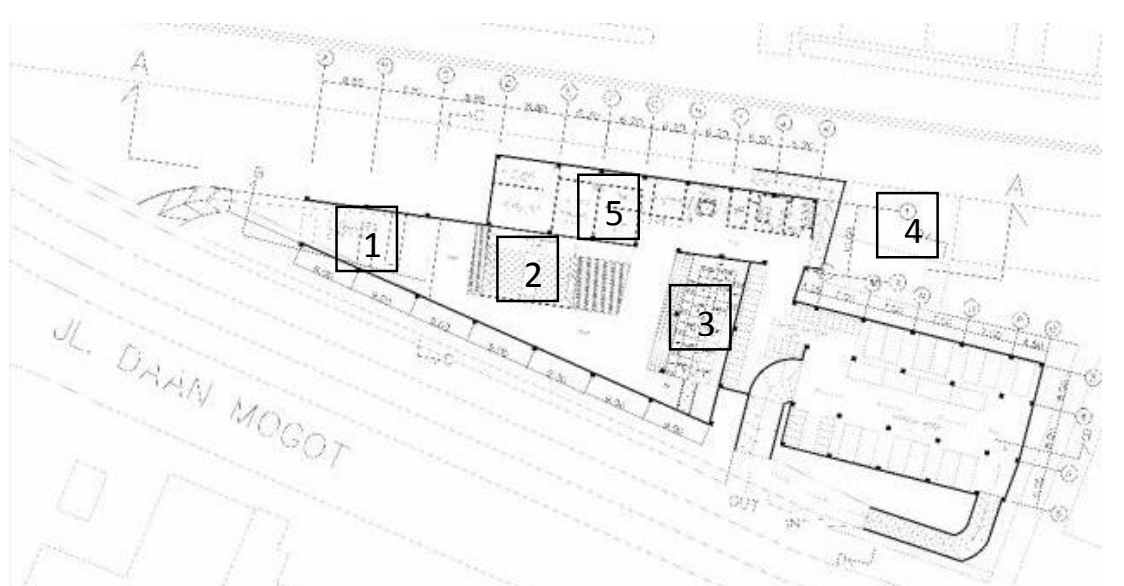

1. Basement, 2. Service, 3. Pedestrian mall, 4. Theater Outdoor, 5. Foodstreet

Gambar 6. Denah basement

Sumber: Penulis, 2019 
Denah basement ini, tidak hanya menyediakan parkir untuk pengelola maupun karyawan lainya dan area servis untuk utilitas bangunan, karena untuk meminimalisir kebisingan akibat kereta api, ditambah dengan ktivitas lokal didalamnya seperti theater outdoor, pedestrianmall, dll, karena dengan lahan minim, dengan program yang cukupbanyak, maka diletakan diantara parkir kendaraan dengan area servis.

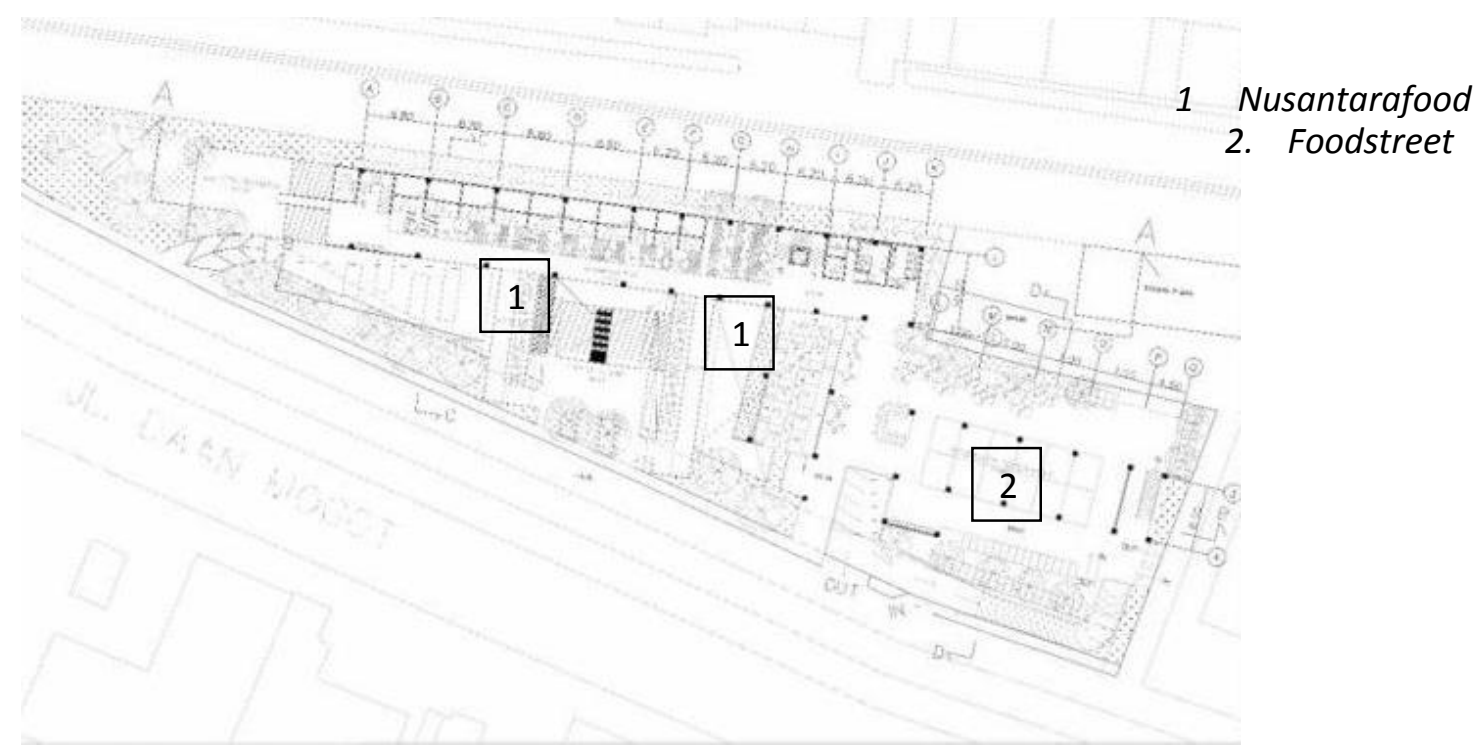

Gambar 7. Denah lantai dasar

Sumber: Penulis, 2019

Di lantai dasar, terdapat aktivitas utamanya yaitu tempat kuliner nusantara dan foodstreet, dimana terdapat jenis-jenis makanan nusantara dan tempat untuk mereka beristirahat, tetapi tidak hanya untuk menikmati makanan saja, pengunjung juga bisa melihat" galeri nusantara yang berada di tempat kuliner tersebut. Untuk menghindari bisingnya kendaraan maupun kereta api, posisi tempat kuliner berada di tengah site dan penghijauan, sehingga pengunjung merasa nyaman berada disana.

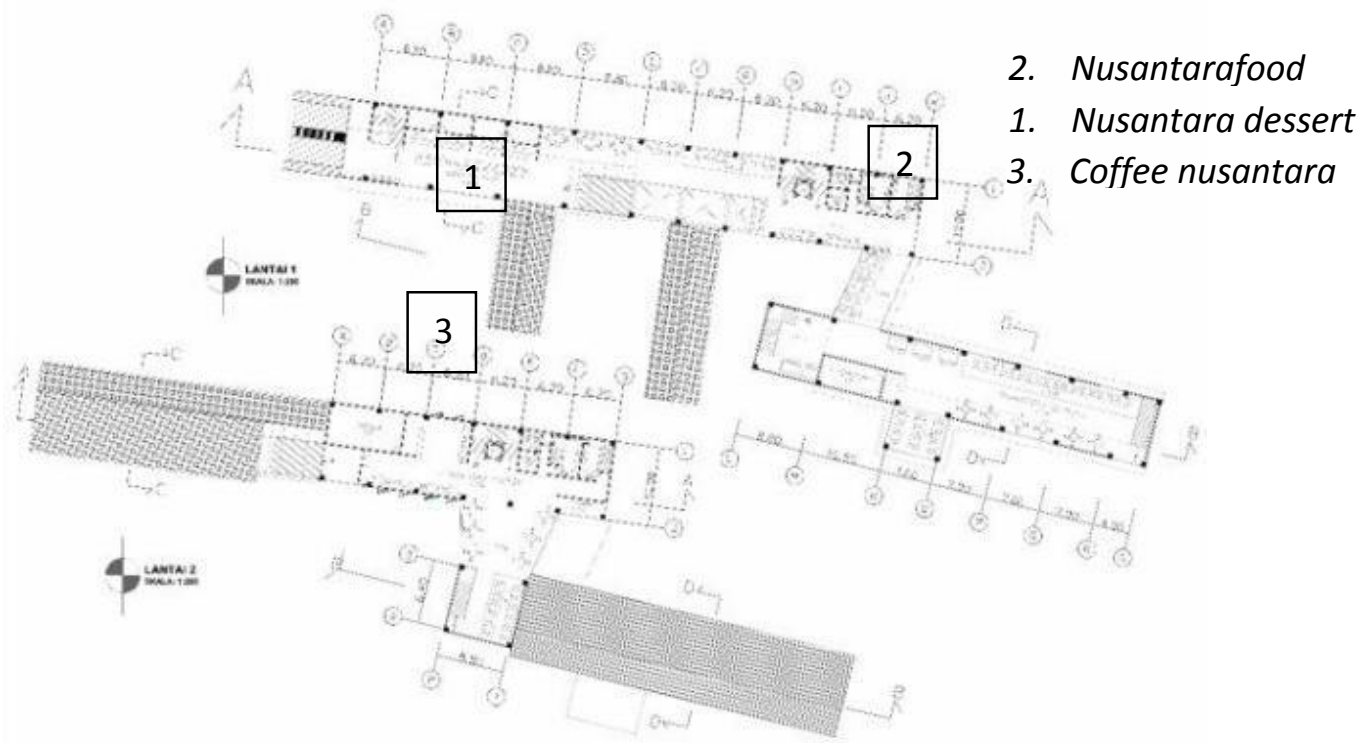

Gambar 8. Lantai 1 dan 2

Sumber: Penulis, 2019 
Untuk lantai 1 dan 2 program tambahan di area kulineri, dan tempat makanan penutup nusantara, sehingga semua pengunjung lokal maupun turispun bisa mencobanya, dan disana terdapat galeri juga sesuai zona yang ada. Tidak hanya itu, cafe nusantara menjadi penghubung antara co-working space dengan tempat kuliner nusantara.

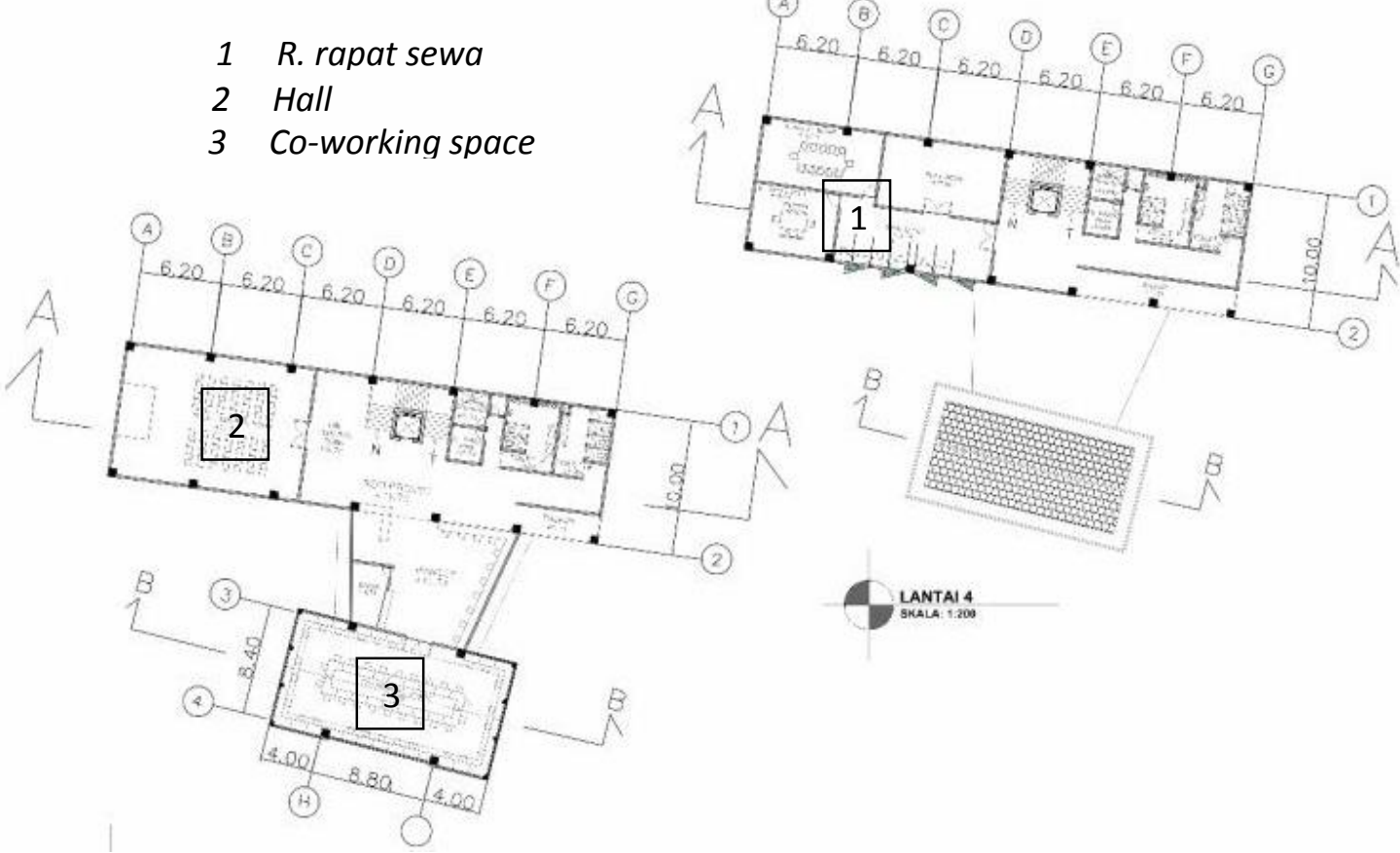

Gambar 9. lantai 3 dan 4

Sumber: Penulis, 2019

Untuk lantai 3 dan 4 saya letakan ruang rapat sewa dan co working space yang menjadi program pendukung di rancangan ini, karena dekat dengan stasiun, sehingga orang yang bekerja disini tidak perlu mencari makanan diluar area ini, karena disini sudah di sediakan semua jenis makanan dan minuman.

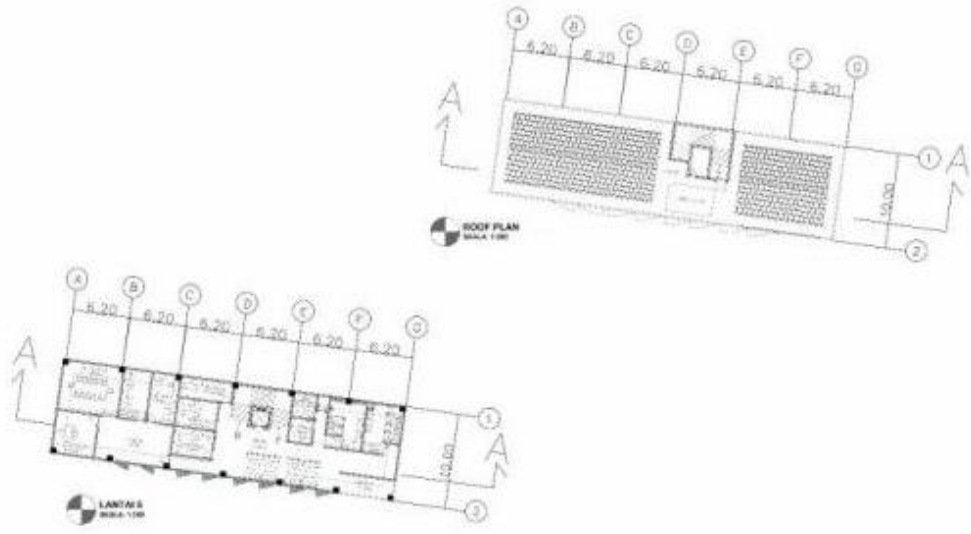

Gambar 10. lantai 5 dan rencana Sumber: Penulis, 2019

Di lantai 5 terdapat kantor untuk gedung pengelola, karena lokasi yang private dan strategis di paling atas dan mudah untuk mengawasi kegiatan di tempat kuliner ini serta jauh dari kebisingan. 


\section{KESIMPULAN DAN SARAN \\ Kesimpulan}

Kelurahan Wijaya kesuma yang tepatnya di area stasiun pesing, sekaligus menjadi titik kemacetan lokal di Jl Daanmogot Raya dan kurangnya tempat makan yang bersih, dan terintegrasi. Yang disebabkan oleh banyaknya pedagang kaki lima yang kotor di sekitar stasiun pesing, banyaknya ojek online yang menghambat jalan danmogot, RTH yang kurang memadai di area kelurahan Wijaya kesuma, dan tidak ada tempat bekerja yang menyenangkan. Food advanture place adalah rancangan yang akan menjadi sebuah solusi untuk masyarakat perkotaan dari kalangan menengah ke bawah sampai keatas, dan menjadi sebuah thirdplace bagi warga wilayah grogol petamburan. Karena dengan adanya nusantara foodstreet, nusantara food, theater outdoor, RTH yang bersih, dan sederhana, serta dikombinasikan dengan tempat kerja yang menyenangkan, seluruh masyarakat akan menikmati suasana tersebut dan dapat meminimalisir kemacetan yang berada di depan gang stasiun pesing.

\section{Saran}

Saran penulis adalah buatlah ruang ketiga yang menyenangkan di tempat perbatasan antara ruang pertama dan kedua, karena ruang ini sangat dibutuhkan di seluruh kehidupan manusia untuk mendukung jatidiri dan memotivasi agar tetap menjalankan aktivitasnya dengan maksimal.

\section{REFERENSI}

Ariffin, R.N.R., Zahari, R.K. (2013). The Challenges of Implementing Urban Transport Policy in The Klang Valley, Malaysia. Procedia Environmental Sciences. 17 (2013). pp. 469-477.

Danoe, I. (2006). Pengaruh Elemen Elemen Pelengkap Jalur Pedestrian terhadap Kenyamanan Pejalan Kaki (Studi Kasus Penggal Jalan Pandanaran Dimulai dari Jalan Randusari Hingga Kawasan Tugu Muda). ENCLOSURE, 5 (1). pp. 21-29.

Oldenburg, R. (1989). The Great Good Place. Cambridge Centre, USA: Paragon House.

Pattisinai, A.R. (2013). Kajian Kualitas Jalan Pahlawan Sebagai Jalur Pejalan Kaki di Kota Semarang. Jurnal Pembangunan Wilayah \& Kota, vol. 9, no. 3, pp. 248-258

Peterson, C (2009). Happy Places: Third Places (third places are where people congregate besides work or home). https://www.psychologytoday.com/us/blog/the-goodlife/200912/happy-places-third-places

Weston, R. (2011). 101 Ideas that Changed Architecture. London: Lawrence King Publishers. 
